\title{
Development of gastroretentive floating granules with gentian root extract by hot-melt granulation
}

\author{
Jelena Mudrić $^{1 *}$, Mirjana Pajić ${ }^{2}$, Dubravka Bigović ${ }^{1}$, And Jelena Đuriš ${ }^{2}$ \\ ${ }^{1}$ Institute for Medicinal Plants Research "Dr. Josif Pančić", Tadeuša Košćuška 1, 11000 Belgrade, Serbia \\ ${ }^{2}$ University of Belgrade, Faculty of Pharmacy, Department of Pharmaceutical Technology and Cosmetology, Vojvode Stepe 450, 11221 Belgrade, Serbia \\ *Corresponding author: jmudric@mocbilja.rs
}

Received: November 3, 2020

Accepted: December 1, 2020

Published on-line: December 14, 2020

Published: December 25, 2020

\begin{abstract}
The roots of yellow gentian, Gentiana lutea $\mathrm{L}$. (Gentianaceae) are used in traditional medicine for the treatment of gastrointestinal disorders, with the literature data indicates a local gastric effect of gentian root extract (GRE) and support the use of the solid pharmaceutical forms. Gentiopicroside, as a dominant secoiridoid in the GRE, has a short elimination half-life and low bioavailability and, consequently, its bioactivity is limited. The aim of the study was to develop gastroretentive floating delivery system with GRE, and to provide prolonged release of gentiopicroside. Floating granules with dry GRE (DGRE) were prepared by the hot-melt granulation technique, while formulations included effervescent components (citric acid and sodium bicarbonate), hydroxypropyl methylcellulose (HPMC) and meltable binders (Compritol ${ }^{\circledR} 888$ ATO and Gelucire ${ }^{\circledR}$ 50/13). The flowability of the DGRE and prepared formulations was determined by calculating the Carr index and Hausner ratio. Floating properties and in vitro dissolution rate of gentiopicroside from investigated formulations were examined. Floating granules were characterized with improved flowability (Carr index 14-22 \%; Hausner ratio 1.16-1.28) in comparison to the DGRE (Carr index $28.99 \%$; Hausner ratio of 1.41). Furthermore, the floating granules exhibited immediate and long-lasting buoyancy and prolonged-release of gentiopicroside (over $8 \mathrm{~h}$ ). Compritol ${ }^{\circledR} 888$ ATO has provided sustained release of gentiopicroside from floating granules, while HPMC has decreased release rate additionally. On the other hand, Gelucire ${ }^{\circledR}$ 50/13 has increased gentiopicroside release rate. The results have shown that hot-melt granulation technique, as a green granulation method was successfully employed for obtaining gastroretentive floating granules with DGRE.
\end{abstract}

Key words: $\quad$ Gentiana lutea; gentiopicroside; prolonged release; Compritol ${ }^{\circledR} 888$ ATO; HPMC; Gelucire ${ }^{\circledR}$ 50/13.

http://dx.doi.org/10.5937/leksir2040040M

\section{INTRODUCTION}

Underground parts of yellow gentian, Gentiana lutea L. (Gentianaceae) are used in traditional medicine for the treatment of gastrointestinal disorders, such as dyspepsia, liver dysfunction, loss of appetite, while it is official in the European and many nationals Pharmacopoeias (Šavikin et al., 2015; Ph. Eur. 10.0, 2020). Previous studies have shown choleretic (Öztürk et al., 2002), anti-inflamtory (Mathew et al., 2004), antiulcerogenic (Niiho et al., 2006), radioprotective (Menković et al., 2010), analgesic (Öztürk et al., 2002) and antimicrobial (Pontus et al., 2006) activity of gentian root extract. Beneficial health effects of gentian root extract are associated with the presence of bitter-tasting secoiridoids (gentiopicroside, sweroside, swertiamarin, loganic acid) and biphenyl derivatives (amarogentin, amaropanin and amaroswerin), as well as phenolics i.e. xanthones (isogentisin, gentioside, gentisin), and flavonoids (isovitexin, isoorientin) (Šavikin et al., 2015; Živković et al., 2019). Gentiopicroside is the dominant bioactive compound in the gentian root extract with choleretic, hepatoprotective, adaptogenic and anti-inflammatory activities (Wu et al., 2017). However, there are obstacles, due to suboptimal pharmacokinetic properties of gentiopicroside, such as short elimination half-life (2.8 h) and low bioavailability (39.6\%), reported after animal studies (Wang et al., 2004) that limit its bioactive potential. Therefore, there is a need to formulate delivery systems with prolonged release of gentian root extract. Furthermore, the literature data indicate a local gastric effect of gentian root extract and support the use of the solid pharmaceutical forms (EMA, 2018).

Gastroretentive delivery systems are designed to provide prolonged residence time in the stomach as well as controlled release of active compounds. Such systems are suitable for active compounds with the local effect in the stomach, short 
elimination half-life, higher absorption in the upper part of the gastrointestinal tract or in the case of active compounds instability in the intestine at higher $\mathrm{pH}$ (Lopes et al., 2016; Tripathi et al., 2019). Shah et al. (2009) have reviewed gastroretentive floating delivery systems for Helicobacter pylori eradication with herbal drugs. In addition, Prasanthi (2019) has presented gastroretentive tablets of Coccinia grandis leaf extract for treating H. pylori infection. Zhang et al. (2018) have demonstrated enhanced gastric therapeutic effects of Brucea javanica oil formulated in a gastrorentive delivery system, compared to the commercial products. Kim et al. (2017) have demonstrated, in in vivo studies, the gastroprotective effects of Artemisia princeps gastroretentive floating tablets. Efficient antiulcer gastroretentive systems have been developed for Boswellia oleogum resin (Yusif et al., 2016) and aspen bark dry extract (Krylova et al., 2018).

Floating drug delivery systems are gastroretentive delivery systems with lower density compared to the gastric fluid $\left(1.004 \mathrm{~g} / \mathrm{cm}^{3}\right)$ (Tripathi et al., 2019). Therefore, these systems float on the surface of the gastric fluid and remain in the stomach longer, while the active principles are released from the system at the desired, modified rate. Multiple-unit gastroretentive delivery systems, such as floating granules have been proposed to overcome the risk of losing effect too early due to "all-or-none" emptying from the stomach related to single-unit dosage forms (Mishra and Dhole, 2019; Zhai et al., 2014). The hot-melt granulation technique is recognized as an environmentally-friendly solvent-free green method that can be utilized for the preparation of gastroretentive floating delivery systems (Aoki et al., 2015; Khaled et al., 2020; Shimpi et al., 2004; Zhai et al., 2014). Futhermore, meltable binders that enable the hot-melt granulation, may also sustain the active ingredients release rate and provide floating due to the hydrophobic nature (Patel et al., 2018).

There is an unmet need in developing formulations with gentian root extract that could stay in the stomach, as the targeted site of action, for prolonged periods of time. The development of gastroretentive formulations is considered as a viable approach that could lead to an increase in the therapeutic efficacy and reduction in the dosing frequency. Therefore, the aim of the presented study was to develop gastroretentive floating delivery system, by using the hot-melt granulation technique, and to provide prolonged release of active compounds from gentian root extract. Gentiopicroside, selected as a marker compound, is expected to be released in a continuous manner. The effect of lipid excipients (Compritol ${ }^{\circledR} 888$ ATO and Gelucire $^{\circledR}$ 50/13) and hydrophilic polymer (hydroxypropyl methylcellulose) on flowability, floating time and gentiopicroside release rate was investigated.

\section{MATERIALS AND METHODS}

\subsection{Plant material and chemicals}

Excipients used for formulation were hydroxypropyl methylcellulose (HPMC, Methocel ${ }^{\circledR}$ E5 LV, Dow ${ }^{\circledR}$, USA), hydrophilic polymer used as a matrix forming excipient, lactose monohydrate was used as a diluent, citric acid and sodium bicarbonate as an effervescent components, while glyceryl behenate (Compritol ${ }^{\circledR} 888$ ATO, Gattefrosse, Saint-Priest, Cedex, France) and stearoyl macrogol-32 glycerides (Gelucire ${ }^{\circledR}$ 50/13, Gattefrosse, Saint-Priest, Cedex, France) were used as meltable binders. Ethanol 96 \% (v/v) (Honeywell Riedel de Haën, Seelze, Germany), orthophosphoric acid (Sigma-Aldrich Chemie GmbH, Münich, Germany), acetonitrile (Merck, Germany) was HPLC grade and ultra-pure water was prepared using a Milli-Q purification system (Millipore, France). Gentiopicroside (ChromaDex, USA) standard was used. All excipients, reagents and standards used were of analytical grade.

\subsection{Preparation of dry extract}

Plant material, Gentiana lutea roots, was purchased from the Institute for Medicinal Plants Research "Dr. Josif Pančić" (Belgrade, Serbia). Liquid gentian root extract was obtained by heat-assisted extraction under the optimal conditions described by Mudrić et al. (2020). Extraction in a thermostated water bath (Grant, model LSB 18, United Kingdom) lasted 129 minutes, at a temperature of $65^{\circ} \mathrm{C}$, ethanol concentration was $49 \%$ and the solid-to-solvent ratio was 1:40. After filtration, the liquid extract was dried in a laboratory spray dryer. The inlet temperature was $95^{\circ} \mathrm{C}$, the outlet temperatures varied between $50-70{ }^{\circ} \mathrm{C}$, the feed flow rate of the extract was $22 \mathrm{rpm}$ Obtained dry gentian root extract was used in all prepared formulations.

\subsection{Preparation of formulations}

Five formulations were prepared according to the Table 1. Physical mixture of powders (formulation A) was prepared by mixing of dry gentian root extract, lactose monohydrate, HPMC, effervescent components (citric acid and sodium bicarbonate) according to the principle of compound powder production. Formulations B, C, D and E were prepared by the hot-melt granulation. Powder mixture was added to melted binder (Compritol ${ }^{\circledR}$ or mixture of Compritol ${ }^{\circledR}$ and Gelucire ${ }^{\circledR}$ $50 / 13$ ) at a temperature of $75^{\circ} \mathrm{C} \pm 2{ }^{\circ} \mathrm{C}$, with continuous stirring. After cooling, obtained mass was crushed, with a mortar and pestle and granulate was sieved through a $250 \mu \mathrm{m}$ sieve.

\subsection{Micromeritic properties}

Bulk density was determined by measuring the mass of a known volume of powder in a beaker. Tapped density was determined in a vibrating volumeter (Stampfvolumeter STAV 2003, Jel, Germany). Based on the data on bulk and tapped density, it is possible to define the flowability of granules by calculating Carr index and Hausner ratio as follows:

$$
\begin{gathered}
\text { Carr index }(\%)=\frac{\text { tapped density }- \text { bulk density }}{\text { tapped density }} \times 100 \\
\text { Hausner ratio }=\frac{\text { tapped density }}{\text { bulkdensity }}
\end{gathered}
$$

The powder/granules flow classification was performed according to the European Pharmacopoeia 10.0 (Ph. Eur. 10.0, 2020).

\subsection{Floating investigation}

Formulations A, B, C, D and E were placed in $500 \mathrm{~mL}$ (37 $\left.{ }^{\circ} \mathrm{C} \pm 0.5^{\circ} \mathrm{C}\right)$ of $0.1 \mathrm{M} \mathrm{HCl}(\mathrm{pH}=1.2)$ in the type II dissolution apparatus (apparatus with rotating paddle, Erweka DT600, Germany). The medium was agitated by paddle at $50 \mathrm{rpm}$. The time taken by the powder/granules ( $8 \mathrm{~g}$ of each formulation) to rise over the surface of the medium (floating lag time) and total floating time was measured visually (Mishra and Dhole, 2019).

\subsection{In vitro dissolution rate of gentiopicroside and floating properties of the formulations}

The dissolution tests were performed in triplicate using apparatus type II (apparatus with rotating paddle, Erweka DT600, Germany) with a paddle rotation speed of $50 \mathrm{rpm}$. Dissolution medium consisted of $500 \mathrm{~mL}$ of $0.1 \mathrm{M} \mathrm{HCl}(\mathrm{pH}=1.2)$ heated to $37^{\circ} \mathrm{C} \pm 0.5^{\circ} \mathrm{C}$. The weight of the powder/granules used for the test was $8 \mathrm{~g}$. The sample $(4 \mathrm{~mL})$ was taken after certain time intervals and the medium was replenished after each sampling. After filtration, the amount of dissolved gentiopicroside was analyzed by high pressure liquid chromatography (HPLC). 


\subsection{Determining the content of gentiopicroside by HPLC}

Analyses were carried out on an Agilent 1200 RP HPLC instrument, with diode array detector (DAD) and a reverse phase Zorbax $\mathrm{SB}_{-} \mathrm{C}_{18}$ analytical column $(150 \mathrm{~mm} \times 4.6 \mathrm{~mm} ; 5 \mu \mathrm{m}$ particle size) at a temperature of $25^{\circ} \mathrm{C}$ according to the previously described method (Balijagić et al., 2012). The mobile phase consisted of solvent A $(1 \% \mathrm{v} / \mathrm{v}$, solution of orthophosphoric acid in water) and solvent $\mathrm{B}$ (acetonitrile) using an gradient elution as follows: 0-5 $\mathrm{min}, 98-90 \% \mathrm{~A} ; 5-15 \mathrm{~min}, 90$ $\%$ A; 15-20 min, 90-85 \% A; 20-25 min, 85-70 \% A; 25-30 min $70-40 \%$ A; 30-34 min, 40-0 \% A. The injection volume was 5 $\mu \mathrm{L}$. Detection wavelength was set at $260 \mathrm{~nm}$ and the flow rate was $1 \mathrm{~mL} / \mathrm{min}$. The amounts of the dissolved gentiopicrosde was calculated using calibration curve.

Table 1. Composition of prepared formulations

\begin{tabular}{lrrrrr}
\hline & \multicolumn{5}{c}{ Formulation codes } \\
\cline { 2 - 6 } Ingredients & $\mathrm{A}$ & $\mathrm{B}$ & $\mathrm{C}$ & $\mathrm{D}$ & $\mathrm{E}$ \\
{$[\%]$} & {$[\%]$} & {$[\%]$} & {$[\%]$} & {$[\%]$} \\
\hline DGRE $^{\mathrm{a}}$ & 25 & 25 & 25 & 25 & 25 \\
HPMC $^{\mathrm{b}}$ & 15 & 15 & 15 & 15 & - \\
Lactose, monohydrate & 45 & 25 & 15 & 13 & 30 \\
Effervescent components $^{\mathrm{c}}$ & 15 & 15 & 15 & 15 & 15 \\
Compritol $^{\circledR} 888$ ATO & - & 20 & 30 & 30 & 30 \\
Gelucire $^{\circledR} 50 / 13$ & - & - & - & 2 & - \\
\hline
\end{tabular}

a DGRE - dry gentian root extract

b HPMC-hydroxypropyl methylcellulose

${ }^{c}$ Citric acid and sodium bicarbonate in the ratio of $0.76: 1$

\section{RESULTS AND DISCUSSION}

The flowability of the dry gentian root extract, and prepared formulations, was determined by calculating Carr index and Hausner ratio (Table 2). Dry gentian root extract has exhibited poor flowability with Carr index of $28.99 \%$ and Hausner ratio of 1.41 , which could be attributed to the sticky nature of the extract. Furthermore, poor flowability of formulation A has indicated that the addition of HPMC, lactose, and effervescent compounds (sodium hydrogen carbonate and citric acid) to gentian root extract has not enhanced flowability. Granules with gentian root extract obtained by the hot-melt granulation (formulations B, C, D and E) were characterized by improved flowability (Carr index 14-22 \%; Hausner ratio 1.16-1.28) in comparison to the gentian root extract and formulation A.

Flowability of granules with the highest content of lipid excipients (formulation D) was superior to the flowability of granules with lower content of lipid excipients. This result has indicated that the hot-melt granulation has a positive influence on the flowability of gentian root extract and that the addition of lipid excipients is related to the improved flowability. This finding is in accordance with a previous study where the influence of hot-melt granulation on the flowability of divalproex was investigated (Khaled et al., 2020).

Furthermore, lipid-based floating multiparticulate delivery systems with berberine hydrochloride as active compound and lipid carrier Gelucire ${ }^{\circledR} 43 / 01$ as release retardant, HPMC $\mathrm{K} 4 \mathrm{M}$ as matrix polymer and sodium bicarbonate as a gas former were characterized with fair to good flowability (Mishra and Dhole, 2019).
Table 2. Carr index and Hausner ratio of prepared formulations and gentian root extract

\begin{tabular}{lrrr}
\hline & $\begin{array}{r}\text { Carr index } \\
{[\%]}\end{array}$ & Hausner ratio & Flowability \\
\hline DGRE $^{\mathrm{a}}$ & 29 & 1.41 & Poor \\
$\mathrm{A}$ & 30 & 1.43 & Poor \\
$\mathrm{B}$ & 20 & 1.25 & Fair \\
$\mathrm{C}$ & 20 & 1.25 & Fair \\
$\mathrm{D}$ & 14 & 1.16 & Good \\
$\mathrm{E}$ & 16 & 1.19 & Fair \\
\hline
\end{tabular}

${ }^{a}$ DGRE - dry gentian root extract

\subsection{In vitro characterization of formulations}

All investigated formulations have floated all the time during the dissolution test. There was no floating lag time for any formulations. This feature could be due to the lipophilic nature and low density $(0.46 \mathrm{~g} / \mathrm{mL})$ of Compritol ${ }^{\circledR}$. The same finding was reported when Compritol ${ }^{\circledR}$ was used to formulate a self-emulsifying floating drug delivery system with tetrahydrocurcumin (Setthacheewakul et al., 2011). Furthermore, gas $\left(\mathrm{CO}_{2}\right)$ was formed by the reaction of a base (sodium bicarbonate) and acidic component (citric acid) of the formulation in the presence of dissolution medium, while the density of dosage forms decreased due to incorporation of generated gas in HPMC matrix.

The influence of Compritol ${ }^{\circledR}$, Gelucire ${ }^{\circledR} 50 / 13$ and HPMC on the gentiopicroside release behavior from the obtained floating granules (formulations B, C, D and E) and powder (formulaton A) was investigated. Release of gentiopicroside from formulation A was rapid and more than $37.23 \%$ of gentiopicroside was dissolved in $1 \mathrm{~h}$. On the other hand, a significant decrease in the release rate of gentiopicroside was observed in the case of granules obtained by the hot-melt granulation (formulations B, C, D and E). It can be noticed that after the burst release of gentiopicroside $(21.98 \%$ ) in the first $30 \mathrm{~min}$ from formulation $\mathrm{A}$, in the second phase gentiopicroside release was slower. It was reported previously that release from HPMC based gastric floating drug delivery system appear to be bi-phasic with initial burst effect (less than $30 \mathrm{~min}$ ) followed by a polymercontrolled slower release in the second phase (Li et al., 2003), while both diffusion and erosion mechanisms contribute to the controlled release of active substances (Zhai et al., 2014). By comparing the dissolution rates of formulations A and B after 60 minutes, it is clear that the addition of Compritol ${ }^{\circledR}(20$ $\%)$ has prevented the initial burst effect, and dissolution rate of gentiopicroside was significantly decreased, due to the pronounced hydrophobic nature of Compritol ${ }^{\circledR}$, that facilitates the sustained release of active compounds (Figure 1).

Khaled et al. (2020) have reported that Compritol ${ }^{\circledR} 888$ ATO (glyceryl behenate) has enabled prolonged release of divalproex and release was slower than in the case of meltable binders such as Geleol ${ }^{\circledR}$ (glyceryl monostearate), Precirol ${ }^{\circledR}$ ATO5 (glyceryl palmitostearate), and Gelucire ${ }^{\circledR}$ 50/13 (Stearoyl macrogol-32 glycerides). By comparing gentiopicroside release from formulation B $(28.61 \%)$ and C (23.71 $\%$ ) minor changes are noticed after $240 \mathrm{~min}$, indicating that the increase in the amount of Compritol ${ }^{\circledR}$ (from $20 \%$ to $30 \%$ ) has a negligible effect on dissolution rate. Formulation $\mathrm{D}$ with a mixture of meltable binders (Gelucire ${ }^{\circledR} 50 / 13$ and Compritol ${ }^{\circledR}$ ) was characterized with increased gentiopicroside release rate in comparison to formulation $\mathrm{C}$ with $\mathrm{Compritol}^{\circledR}$, as meltable 


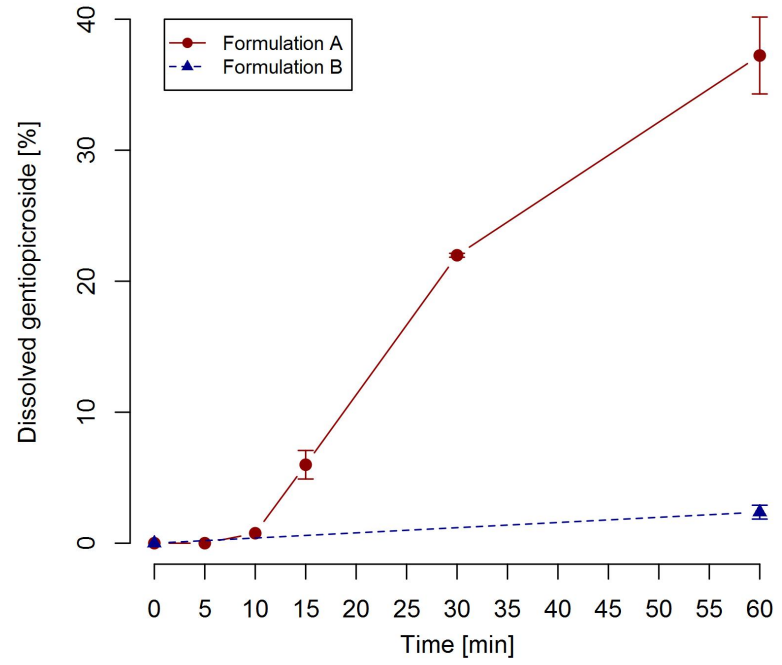

Fig. 1. Gentiopicroside release profile from formulations A and B

binder (Figure 2). This result is in accordance with the study of Zhai et al. (2014) where it was noticed that metronidazole release rate was increased, after the addition of Gelucire ${ }^{\circledR}$ $50 / 13(2-4 \%)$, as a bioavailability and solubility enhancer, to the formulation of gastroretentive extended-release floating granules, while addition of higher concentration (10-15\%) Gelucire ${ }^{\circledR} 50 / 13$ resulted in loss of sustained release. The effect of HPMC on the release was evident when the percentage of dissolved gentiopicroside from formulation C (50.95 $\%)$ and E (100.46\%) after $8 \mathrm{~h}$ were compared. Gentiopicroside release from formulation $\mathrm{E}$ was characterized as bi-phasic with initial slower release and faster release in the second phase. The increased release rate in the second phase could be a consequence of increased diffusion of dissolution medium in floating granules without HPMC, due to the absence of gelatinous layer formed in contact of hydrophilic polymer and dissolution medium. A control over gentiopicroside release rate is necessary, in order to avoid incomplete release that can occur in the case of lipid-based delivery systems (Knežević et al., 2009).

\section{CONCLUSION}

In this study, the hot-melt granulation technique, as a green granulation method was successfully employed for obtaining gastroretentive floating granules with gentian root extract. The obtained floating granules were characterized with improved flowability, immediate and long-lasting floating and prolonged-release (over $8 \mathrm{~h}$ ) of gentiopicroside, as a marker compound in the gentian root extract. Compritol ${ }^{\circledR} 888$ ATO $(20-30 \%)$ used as a meltable binder has provided sustained release of gentiopicroside from floating granules, while HPMC $(15 \%)$ as a hydrophilic polymer has decreased release rate additionally. On the other hand, Gelucire ${ }^{\circledR} 50 / 13$ (2\%) has increased release rate of gentiopicroside. Therefore, gastroretentive floating granules with Compritol ${ }^{\circledR} 888$ ATO and addition of Gelucire ${ }^{\circledR} 50 / 13$ and HPMC could be used for targeted and sustained release of gentian root extract in the stomach. Further development, optimization and in vitro and in vivo evaluation of prepared floating systems could contribute to gentian root extract efficiency, in terms of reduced dosing frequency and ease of formulated product administration.

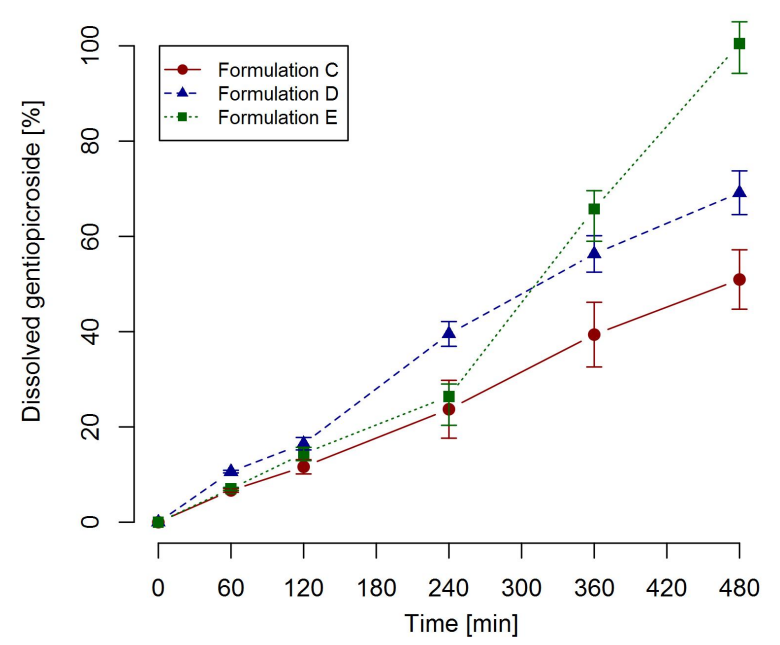

Fig. 2. Gentiopicroside release profile from formulations $C, D$ and $E$

\section{ACKNOWLEDGMENTS}

This research was supported by the Ministry of Education, Science and Technological Development of Republic of Serbia, contract numbers 451-03-68/2020-14/200003 and 451-03 68/2020-14/200161.

\section{REFERENCES}

Aoki, H., Iwao, Y., Mizoguchi, M., Noguchi, S. and Itai, S. (2015). Clarithromycin highly-loaded gastro-floating fine granules prepared by high-shear melt granulation can enhance the efficacy of Helicobacter pylori eradication, European Journal of Pharmaceutics and Biopharmaceutics 92: 22-27.

Balijagić, J., Janković, T., Zdunić, G., Bošković, J., Šavikin, K., Gođevac, D., Stanojković, T., Jovančević, M. and Menković, N. (2012). Chemical profile, radical scavenging and cytotoxic activity of yellow gentian leaves (Genitaneae luteae folium) grown in northern regions of Montenegro, Natural Product Communications 7(11): 1934578X1200701.

EMA (2018). European medicines agency, assessment report on Gentiana lutea 1., radix. Ref.: EMA/HMPC/607863/2017.

Khaled, A., Abdel-Hamid, S., Nasr, M. and Sammour, O. A. (2020). Fabrication of extended-dissolution divalproex tablets: a green solvent-free granulation technique, Drug Development and Industrial Pharmacy 46(6): 975-987.

Kim, J.-I., Park, S.-W., Lim, J.-J., Sohn, S.-I., Shin, J.-S., Park, S. C., Jang, Y. P., Chung, E. K., Lee, H.-W. and Lee, K.-T. (2017). Gastroprotective effects of the isopropanol extract of Artemisia princeps and its gastroretentive floating tablets on gastric mucosal injury, Acta Pharmaceutica 67(4): 479-494.

Knežević, Z., Gosak, D., Hraste, M., Rausl, D. and Khan, M. I. (2009). Application of hot-melt coating process for designing a lipid based controlled release drug delivery system for highly aqueous soluble drugs., Chemical and pharmaceutical bulletin, 57(5): 464-471.

Krylova, S. G., Turetskova, V. F., Makarova, O. G. and Zueva, E. P. (2018). Technology development and antiulcer activity of gastroretentive tablets with aspen bark dry extract, Pharmaceutical Chemistry Journal 52(2): 133-138. 
Li, S., Lin, S., Daggy, B. P., Mirchandani, H. L. and Chien, Y. W. (2003). Effect of HPMC and Carbopol on the release and floating properties of Gastric Floating Drug Delivery System using factorial design, International Journal of Pharmaceutics 253(1-2): 13-22.

Lopes, C. M., Bettencourt, C., Rossi, A., Buttini, F. and Barata, P. (2016). Overview on gastroretentive drug delivery systems for improving drug bioavailability, International Journal of Pharmaceutics 510(1): 144-158.

Mathew, A., Taranalli, A. D. and Torgal, S. S. (2004). Evaluation of anti-inflammatory and wound healing activity of Gentiana lutea rhizome extracts in animals, Pharmaceutical Biology 42(1): 8-12.

Menković, N., Juranić, Z., Stanojković, T., Raonić-Stevanović, T., Šavikin, K., Zdunić, G. and Borojević, N. (2010). Radioprotective activity of Gentiana lutea extract and mangiferin, Phytotherapy Research 24(11): 1693-1696.

Mishra, R. and Dhole, S. (2019). Lipid-based floating multiparticulate delivery system for bioavailability enhancement of berberine hydrochloride, Journal of Applied Pharmaceutical Science, 9(11): 036-047.

Mudrić, J., Janković, T., Šavikin, K., Bigović, D., Đukić Ćosić, D., Ibrić, S. and Đuriš, J. (2020). Optimization and modelling of gentiopicroside, isogentisin and total phenolics extraction from Gentiana lutea L. roots, Industrial Crops and Products 155: 112767.

Niiho, Y., Yamazaki, T., Nakajima, Y., Yamamoto, T., Ando, H., Hirai, Y., Toriizuka, K. and Ida, Y. (2006). Gastroprotective effects of bitter principles isolated from gentian root and swertia herb on experimentally-induced gastric lesions in rats, Journal of Natural Medicines 60(1): 82-88.

Öztürk, N., Başer, K. H. C., Aydin, S., Oztürk, Y. and Caliş, I. (2002). Effects of Gentiana lutea ssp. symphyandra on the central nervous system in mice, Phytotherapy research: PTR 16(7): 627-631.

Patel, A. U., Caudhari, D. V., Shah, P. J. and Shah, S. A. (2018) Hot melt granulation method for the preparation of floating matrix tablets of tolperison hydrochloride, Future Journal of Pharmaceutical Sciences 4(2): 139-149.

Ph. Eur. 10.0 (2020). European Pharmacopoeia, Council of Europe, Strasbourg.

Pontus, S., A.P., M. and Chaim, I. (2006). Use of Gentiana lutea extracts as an antimicrobial agent., European Patent EP1663271.

Prasanthi, D. N. L. (2019). Design and development of gastroretentive tablets of Coccinia grandis leaf extract for treating Helicobacter pylori infection, Asian Journal of Pharmaceutics 13(3): 184-191.

Šavikin, K., Aljančić, I., Vajs, V., Milosavljević, S., Jadranin, M., Đorđević, I. and Menković, N. (2015). Bioactive secondary metabolites in several genera of Gentianaceae species from the central regions of the Balkan Peninsula, in J. J. Rybczyński, M. R. Davey and A. Mikuła (eds), The Gentianaceae - Volume 2: Biotechnology and Applications, Springer, Berlin, Heidelberg, pp. 319-347.

Setthacheewakul, S., Kedjinda, W., Maneenuan, D. and Wiwattanapatapee, R. (2011). Controlled release of oral tetrahydrocurcumin from a novel self-emulsifying floating drug delivery system (SEFDDS), AAPS PharmSciTech 12(1): 152164.
Shah, S. H., Patel, J. K. and Patel, N. V. (2009). Gastroretentive floating drug delivery systems with potential herbal drugs for Helicobacter pylori eradication: a review, Zhong Xi Yi Jie He Xue Bao = Journal of Chinese Integrative Medicine 7(10): 976982.

Shimpi, S., Chauhan, B., Mahadik, K. R. and Paradkar, A. (2004). Preparation and evaluation of diltiazem hydrochloride-gelucire 43/01 floating granules prepared by melt granulation, AAPS PharmSciTech 5(3): 51-56.

Tripathi, J., Thapa, P., Maharjan, R. and Jeong, S. H. (2019). Current state and future perspectives on gastroretentive drug delivery systems, Pharmaceutics 11(193): 1-22.

Wang, C.-H., Wang, Z.-T., Annie Bligh, W. W., White, K. N. and White, C. J. B. (2004). Pharmacokinetics and tissue distribution of gentiopicroside following oral and intravenous administration in mice, European Journal of Drug Metabolism and Pharmacokinetics 29(3): 199-203.

Wu, S., Yang, L., Sun, W., Si, L., Xiao, S., Wang, Q., Dechoux, L., Thorimbert, S., Sollogoub, M., Zhou, D. and Zhang, Y. (2017). Design, synthesis and biological evaluation of gentiopicroside derivatives as potential antiviral inhibitors, European Journal of Medicinal Chemistry 130: 308-319.

Yusif, R. M., Abu Hashim, I. I., Mohamed, E. A. and Badria, F. A.-E. (2016). Gastroretentive matrix tablets of Boswellia oleogum resin: preparation, optimization, in vitro evaluation, and cytoprotective effect on indomethacin-induced gastric ulcer in rabbits, AAPS PharmSciTech 17(2): 328-338.

Zhai, H., Jones, D. S., McCoy, C. P., Madi, A. M., Tian, Y. and Andrews, G. P. (2014). Gastroretentive extended-release floating granules prepared using a novel fluidized hot melt granulation (FHMG) technique, Molecular Pharmaceutics 11(10): 3471-3483.

Zhang, Y., Zhang, L., Zhang, Q., Zhang, X., Zhang, T. and Wang, B. (2018). Enhanced gastric therapeutic effects of Brucea javanica oil and its gastroretentive drug delivery system compared to commercial products in pharmacokinetics study, Drug Design, Development and Therapy 12: 535-544.

Živković, J., Janković, T., Menković, N. and Šavikin, K. (2019). Optimization of ultrasound-assisted extraction of isogentisin, gentiopicroside and total polyphenols from gentian root using response-surface methodology, Industrial Crops and Products 139: 111567. 